\title{
SINTESIS METIL ESTER DARI MINYAK BIJI KEMIRI (Aleurites molluccana) MENGGUNAKAN METODE ULTRASONOKIMIA
}

\author{
Rahmawati Aziz, Aisyah, Asriani llyas \\ Jurusan Kimia, Fakultas Sains dan Teknologi, UIN Alauddin Makassar \\ Email: amma_aziz@ymail.com
}

\begin{abstract}
Using the fuel oil is the basic necessary in the world now. But, the raw material cannot be updated. To ensure the availability of the fuel oil so, the newest of alternative energy is explored it. One of the ways is biodiesel which made from vegetable oil. In this research is resulted from the transesterification reaction between candlenut oil and methanol by utilizing ultrasonic equipment. This research has passed some phases, they are the determining of acid number in oil then continued by creating biodiesel from ultrasonic wave $47 \mathrm{kHz}$. Identification of FTIR and GCMS are two methods which used to analyze the component compound in biodiesel product. The conversion number that be gotten from FAME with reaction of variation time 30, 40 and 50 in succession 0,037\%, $0,029 \%$ and 0,018\%. The result analysis of FTIR shows some of functional groups which are special from biodiesel. While the result of GCMS analysis is known that there are 5 component compounds in biodiesel namely ester methyl palmitic acid, ester methyl olead, stearata ester methyl, linoleic ester methyl and elaidic ester methyl.
\end{abstract}

Keywords: biodiesel, candlenut oil, FTIR, GCMS and ultrasonic

\section{PENDAhUluan}

Kebutuhan bahan bakar minyak merupakan kebutuhan dasar di seluruh dunia saat ini. Bahan bakar minyak ini tidak dapat diperbaharui sehingga suatu saat akan habis jika digunakan secara terus-menerus. Meningkatnya jumlah penduduk saat ini dari tahun ke tahun dan pesatnya pertumbuhan ekonomi, mendorong tingginya aktivitas dan mobilitas masyarakat. Hal ini mengakibatkan tingginya kebutuhan akan energi dari bahan bakar. Bila tidak dapat tercukupi dengan optimal, maka kelangkaan bahan bakar tidak dapat dihindari.

Berbagai dampak negatif dari bahan bakar fosil, mendorong usaha untuk menciptakan energi alternatif yang dapat diperbarui dalam waktu yang relatif singkat dan ramah lingkungan. Energi alternatif dapat berupa biogas, bioetanol, biomassa dan biodiesel. Biodiesel saat ini sudah mulai digunakan sebagai campuran dalam bahan bakar minyak untuk kendaraan. Bahan dasar pembuatan biodiesel ini berasal dari minyak nabati dan minyak hewani.

Umumnya biji-bijian yang menghasilkan minyak dapat dijadikan sebagai bahan dasar pembuatan biodiesel, termasuk biji kemiri. Komponen minyak biji kemiri terdiri dari susunan asam-asam lemak dalam struktur trigliserida yang dapat direaksikan membentuk produk biodiesel (Elviyanti, 2007, hal: 1). Kemiri merupakan salah satu dari ribuan keanekaragaman hayati yang dimiliki Indonesia. 
Indonesia sebagai negara yang memiliki keragaman sumber daya alam memiliki potensi besar untuk dieksplorasi kekayaan alamnya untuk mencari bahan baku pembuatan biodiesel. Diantaranya sawit, kelapa, kacang (peanut), kelor (Moringa oleifera), saga utan (Adenanthera pavonina), kasumba/kembang pulu (Carthamus tinctorius), jarak pagar (Jatropha curcas), kapok, kemiri, nimba (Azadirachta indica), nyamplung (Calophyllum inophyllum), kesambi (Schleichera oleosa), randu alas (Bombax malabaricum), jarak gurita (Jatropha multifida), jarak landi (Jatropha gossypifolia), dan banyak lagi yang lain (Yuliani, 2013, hal: 2).

Beberapa penelitian tentang produksi biodiesel dari minyak nabati telah banyak dilakukan para peneliti sejak lima tahun terakhir. Hary Sulistyo (2009) memproduksi biodiesel dari minyak biji kemiri melalui proses etanolisis dan menghasilkan nilai konversi minyak sebesar 98,77\%. Dalam penelitiannya, Hary Sulistyo meneliti pengaruh konsentrasi katalis dalam mensintesis minyak biji kemiri menjadi biodiesel. Sementara itu, Nathasya Pamata (2008) dari hasil penelitiannya, menghasilkan minyak biji kemiri dari proses ekstraksi sokhletasi dan rekasi trigliserida menggunakan bantuan gelombang ultrasonik untuk membantu mempercepat reaksi. Nilai konversi dari hasil reaksi transesterifikasi yang dilakukan oleh Nathasya Pamata (2008) yaitu pada waktu reaksi 60 menit dengan perbandingan mol minyak : metanol 1:6 adalah $62,07 \%$.

Berdasarkan penelitian diatas perlu dilakukan penelitian sintesis biodiesel dari minyak biji kemiri menggunakan alat ultrasonik. Sebelumnya telah dilakukan oleh Musadhaz (2013, hal: 1) dalam penelitiannya membuat biodiesel dari minyak kelapa sawit dan minyak biji karet menggunakan instrumen ultrasonik dan menghasilkan nilai konversi minyak sebesar 78,84\% dengan waktu reaksi 30 menit. Penelitian ini berbahan dasar buah kemiri yang dikempak secara konvensional untuk menghasilkan minyaknya.

\section{Tujuan}

Tujuan penelitian Menentukan nilai konversi trigliserida yang dapat diperoleh bila reaksi transesterifikasi menggunakan gelombang ultrasonic dan mengetahui komponen-komponen yang dihasilkan dari reaksi transesterifikasi minyak kemiri menggunakan gelombang ultrasonik.

\section{METODE PENELITIAN}

\section{Alat}

Alat-alat yang digunakan pada penelitian ini antara lain adalah Seperangkat alat FTIR Shimadzu IR-Prestige 21, GS-MS Agilent GC type 7890 A; MS type 5975, ultrasonik Krisbow $47 \mathrm{KHz}$, piknometer, viskometer oswald, seperangkat alat titrasi, oven, penangas listrik, magnetic stirrer, corong pisah, kondensor, termometer, neraca analitik, blender, bejana ukur, 
wadah/bejana, labu erlenmeyer berbagai ukuran, wadah plastik, pipet berbagai ukuran dan batang pengaduk.

\section{Bahan}

Bahan yang digunakan sebagai sampel pada penelitian ini adalah minyak kemiri. Bahan kimia yang digunakan adalah aquades, $\mathrm{KOH}$, metanol, asam asetat glasial, alkohol 96\%, indikator PP, n-heksan, kertas lakmus merah dan $\mathrm{Na}_{2} \mathrm{~S}_{2} \mathrm{O}_{3} 0,1 \mathrm{~N}$.

\section{Prosedur Kerja}

\section{Pembuatan Minyak Kemiri}

Sebelumnya, alat dan bahan disiapkan. Sampel yang telah dirajang dan dihaluskan kemudian ditimbang. Sampel yang ditimbang lalu diangin-anginkan selama \pm 24 jam. Setelah itu, sampel ditimbang kembali lalu dimasukkan ke dalam oven hingga sampel berubah warna menjadi kecoklatan. Hasil pengovenan, disangrai dan dihaluskan dengan cara ditumbuk hingga kemiri berbentuk serbuk (bubuk) lalu ditimbang. Sampel halus dikempa hingga menghasilkan minyak dan setiap 100 gram minyak ditambahkan karbon aktif sebanyak \pm 2 gram. Campuran minyak dan karbon aktif dipanaskan sambil diaduk perlahan lalu disaring dalam keadaan panas.

\section{Penentuan Angka Asam}

Minyak kemiri dipipet sebanyak $10 \mathrm{~mL}$ lalu dimasukkan ke dalam labu alas bulat dengan tambahan metanol 96\% sebanyak $25 \mathrm{~mL}$ lalu direfluks hingga mendidih selama 10 menit. Hasil refluks ditambah beberapa tetes larutan indikator PP lalu dititrasi dengan larutan $\mathrm{KOH} 0,1 \mathrm{~N}$ kemudian mencatat volume larutan.

\section{Penetralan Minyak}

Minyak kemiri murni ditimbang sebanyak 100 gram. Padatan KOH dilarutkan sebanyak 0,0812 gram dilarutkan ke dalam $20 \mathrm{~mL}$ etanol 96\% hingga homogeny. Minyak dicampurkan dengan larutan alkoksida kemudian dipanaskan menggunakan magnetic stirrer dengan suhu $\pm 64^{\circ} \mathrm{C}$ selama 10 menit. Setelah itu, campuran dimasukkan ke dalam corong pisah lalu ditambah $100 \mathrm{~mL}$ n-heksan kemudian dihomogenkan dan didiamkan selama 1 x 24 jam. Setelah didiamkan, campuran dipisah berdasarkan fase yang terbentuk.

\section{Pembuatan Biodiesel}

Timbang padatan $\mathrm{KOH}$ sebanyak 0,13 gram. Padatan yang telah ditimbang kemudian dilarutkan ke dalam metanol 19,2 mL. Larutan alkoksida dicampur dengan minyak yang telah 
ditimbang dengan teliti sebanyak 27,85 gram ke dalam gelas piala $100 \mathrm{~mL}$ lalu diaduk dan dimasukkan ke dalam alat ultrasonik kemudian mengatur waktu pada alat tersebut selama 30 menit.

\section{Pencucian dan Pengeringan}

Biodiesel dan air dicampur kemudian dimasukkan ke dalam corong pisah dan didiamkan selama \pm 60 menit hingga terbentuk dua fase. Pisahkan campuran dengan hati-hati lalu tuang biodiesel (fase atas) ke dalam wadah kering.

\section{Netralisasi}

Tujuan netralisasi untuk meminimalkan sabun terhadap biodiesel yang bersifat basa tersebut, untuk menetralkannya maka ditambahkan larutan asam sebelum dilakukan proses pencucian. Air yang digunakan untuk mencuci terlebih dahulu dicampur dengan asam cuka $\left(\mathrm{CH}_{3} \mathrm{COOH}\right)$ agar biodiesel mencapai $\mathrm{pH} 7$ dengan perbandingan 2:1.

\section{HASIL DAN PEMBAHASAN}

Berdasarkan penelitian yang dilakukan, berikut data yang diperoleh dari hasil pengamatan:

Tabel 1. Variasi Waktu Reaksi Transesterifikasi Metil Ester Dari Minyak Biji Kemiri

\begin{tabular}{cccc}
\hline No. & $\begin{array}{c}\text { Waktu } \\
\text { Reaksi } \\
(\text { menit })\end{array}$ & $\begin{array}{c}\text { Berat Metil } \\
\text { Ester (gram) }\end{array}$ & $\begin{array}{c}\text { Nilai Konversi } \\
(\%)\end{array}$ \\
\hline 1. & 30 & 1,0289 & 0,037 \\
2. & 40 & 0,8051 & 0,029 \\
3. & 50 & 0,5007 & 0,018 \\
\hline
\end{tabular}

Pada penelitian ini, alat ultrasonik berperan sebagai reaktor dalam reaksi transesterifikasi. Reaksi transesterifikasi pada minyak kemiri adalah suatu reaksi yang terjadi dimana trigliserida (ester asam lemak dan gliserol) sebagai minyak nabati, bereaksi dengan metanol dengan penambahan katalis $\mathrm{KOH}$ yang akhirnya akan menghasilkan metil ester asam lemak dan hasil samping gliserol. Jenis alkohol yang digunakan untuk reaksi ini umumnya alkohol berantai pendek seperti metanol dan etanol. Metanol merupakan alkohol yang sangat sering digunakan 
karena sifatnya yang polar dan mudah melarutkan KOH. Selain itu, salah satu keunggulan penggunaan metanol yaitu dapat menghasilkan metil ester yang lebih stabil.

Pada reaksi ini, energi ulrasonokimia (ultrasonik) adalah salah satu faktor yang mempercepat reaksi homogenisasi antara minyak (non polar) dan metanol (polar). Dengan metode ultrasonokimia, proses terjadinya tumbukan antar-molekul minyak dan etanol akan lebih besar dengan proses kavitasi. Proses kavitasi atau pecahnya gelembung dalam pembentukan emulsi ini dapat meningkatkan kecepatan reaksi tersebut. Energi yang besar dari ultrasonik dapat menyebabkan terbentuknya butiran-butiran kecil pada metanol yang dapat menembus lapisan minyak. Terbentuknya butiran kecil pada metanol dapat memperluas area permukaan minyak sehingga reaksi trigliserida oleh katalis $\mathrm{KOH}$ dapat berlangsung.

Waktu reaksi juga salah satu faktor yang sangat mempengaruhi reaksi transesterifikasi. Hal ini terlihat dari hasil penelitian bahwa reaksi dengan waktu reaksi 30 menit merupakan waktu yang optimal berdasarkan hasil konversi metil ester sebesar 0,037\%.

\section{Identifikasi Biodiesel}

Biodiesel murni adalah biodiesel yang bebas dari pengotor-pengotor. Untuk mengidentifikasi sampel biodiesel murni dilakukan beberapa analisis identifikasi yaitu FTIR dan GC-MS.

\section{Analisis FTIR}

Analisis FTIR atau Fourier Transform Infra Red adalah suatu metode analisis yang dipakai mengidentifikasi gugus fungsi dengan cara menentukan dan merekam hasil spektra residu dengan serapan energi oleh molekul organik dalam sinar infra merah. Biodiesel murni dianalisis FTIR untuk membuktikan bahwa reaksi transesterifikasi telah menghasilkan metil ester. Analisis tersebut digunakan untuk mengetahui gugus-gugus fungsi yang terbentuk selain metil ester. Hasil analisis FTIR dari biodiesel dapat dilihat pada Lampiran 1. Spektrum yang dihasilkan dari analisis tersebut berupa pita-pita serapan pada panjang gelombang tertentu.

Tabel 2. Komposisi Gugus Fungsi dari Biodiesel dengan Analisis FTIR dengan Variasi Waktu

\begin{tabular}{lccll}
\hline No. & $\begin{array}{r}\text { Waktu } \\
\text { Reaksi } \\
(\text { menit })\end{array}$ & $\begin{array}{c}\text { Gugus } \\
\text { Fungsi }\end{array}$ & Posisi Serapan & $\begin{array}{c}\text { Serapan } \\
\text { Biodiesel }\end{array}$ \\
\hline 1. & 30 & $\mathrm{C}-\mathrm{O}$ & $1300-1110$ & 1170,$79 ; 1197,79$ \\
& & $\mathrm{C}-\mathrm{C}$ & $1600-1450$ & 1462,04 \\
& & $\mathrm{C}=\mathrm{C}$ & $1700-1600$ & 1651,07 \\
\hline
\end{tabular}




\begin{tabular}{llll}
\hline & C $=$ O & $1750-1725$ & 1741,72 \\
& C - H (Alkana) & $3000-2800$ & 2852,72 \\
& R $=$ CH & $3100-3000$ & 3008,95 \\
& C - H (Metil) & $3000-2800$ & 2926,01 \\
& C - O & $1300-1110$ & 1170,$79 ; 1195,87$ \\
& C - C & $1600-1450$ & 1462,04 \\
& C $=$ C & $1700-1600$ & 1653,0 \\
& C $=$ O & $1750-1725$ & 1739,79 \\
& C - H (Alkana) & $3000-2800$ & 2854,65 \\
& R $=$ CH & $3100-3000$ & 3005,1 \\
& C - H (Metil) & $3000-2800$ & 2926,01 \\
& C - O & $1300-1110$ & 1170,$79 ; 1195,87$ \\
& C - C & $1600-1450$ & 1462,04 \\
& C $=$ C & $1700-1600$ & 1653,0 \\
& C $=$ O & $1750-1725$ & 1739,79 \\
& C - H (Alkana) & $3000-2800$ & 2854,65 \\
& R $=$ CH & $3100-3000$ & 3005,1 \\
& C - H (Metil) & $3000-2800$ & 2926,01 \\
\hline
\end{tabular}

Dari data pada tabel, dapat dilihat bahwa biodiesel yang dihasilkan dari reaksi transesterifikasi menghasilkan produk dengan gugus fungsi khas metil ester, seperti gugus $\mathrm{C}-\mathrm{O}$ pada panjang gelombang 1170,79 dan 1195,$87 ; \mathrm{C}=\mathrm{O}$ pada panjang gelombang 1739,79; $\mathrm{C}=\mathrm{C}$ pada panjang gelombang 1651,07. Gugus fungsi dari hasil analisis FTIR adalah diantaranya gugus metil, gugus ester dan gugus karbonil.

\section{Analisis GC-MS}

Selain analisis FTIR, identifikasi lain dilakukan menggunakan instrumen GCMS. Analisisi GCMS atau Gas Cromatografy Mass Spectrometry merupakan metode pemisahan senyawa organik yang menggunakan dua metode analisis senyawa yaitu kromatografi gas (GC) untuk menganalisis jumlah senyawa secara kuantitatif dan spektrometri massa (MS) untuk menganalisis struktur molekul senyawa analit. Biodiesel hasil reaksi transesterifikasi diuji dengan metode GCMS untuk menentukan struktur senyawa hasil reaksi antara minyak kemiri dan alkohol dengan katalis $\mathrm{KOH}$.

Berdasarkan hasil analisis GCMS maka diperoleh data bahwa hasil reaksi transesterifikasi menghasilkan senyawa metil ester. Struktur dan berat molekul dari hasil analisis dapat dilihat pada lampiran 2. Berikut data kandungan senyawa asam lemak metil ester hasil analisis dalam sampel biodiesel.

Tabel 3. Jenis Senyawa Metil Ester dalam Biodiesel 


\begin{tabular}{clll}
\hline No. & Senyawa Teridentifikasi & $\begin{array}{c}\text { Rumus Molekul } \\
\text { Senyawa }\end{array}$ & Massa Fragmentasi \\
\hline 1. & Asam Palmitat Metil Ester & $\mathrm{C}_{17} \mathrm{H}_{34} \mathrm{O}_{2}$ & $270 ; 227 ; 143 ; 87 ; 74$ \\
2. & Asam Oleat Metil Ester & $\mathrm{C}_{19} \mathrm{H}_{36} \mathrm{O}_{2}$ & $296 ; 264 ; 69 ; 55 ; 41$ \\
3. & Asam Stearat Metil Ester & $\mathrm{C}_{19} \mathrm{H}_{38} \mathrm{O}_{2}$ & $298 ; 255 ; 87 ; 74 ; 43$ \\
4. & Asam Linoleat Metil Ester & $\mathrm{C}_{19} \mathrm{H}_{34} \mathrm{O}_{2}$ & $294 ; 263 ; 67 ; 55 ; 41$ \\
5. & Asam Elaidat Metil Ester & $\mathrm{C}_{19} \mathrm{H}_{36} \mathrm{O}_{2}$ & $296 ; 264 ; 69 ; 55 ; 43$ \\
\hline
\end{tabular}

Senyawa utama yang merupakan komponen-komponen khas dari senyawa yang terkandung dalam biodiesel tersebut dapat dilihat dari besarnya persentase senyawa (Tabel 4). Senyawa lain yang dihasilkan dari analisa GCMS merupakan turunan alkil ester dari masingmasing asam lemaknya.

Tabel 4. Persentase Komposisi Senyawa Hasil Analisis GC-MS

\begin{tabular}{ccccc}
\hline No. Waktu Reaksi & Puncak & $\begin{array}{c}\text { Waktu } \\
\text { Deteksi }\end{array}$ & Persentase \\
& & & \\
\hline & & I & 19.781 & $8.37 \%$ \\
1. & \multirow{3}{*}{30 Menit } & II & 21.439 & $41.70 \%$ \\
& III & 21.496 & $47.05 \%$ \\
& IV & 21.67 & $2.36 \%$ \\
& V & 23.861 & $0.52 \%$ \\
& & I & 14.267 & $5.41 \%$ \\
2. & II & 19.781 & $14.57 \%$ \\
& \multirow{2}{*}{40 Menit } & III & 21.419 & $28.40 \%$ \\
& & IV & 21.477 & $44.44 \%$ \\
& & V & 21.67 & $4.02 \%$ \\
& & I & 14.261 & $5.57 \%$ \\
3. & II & 19.781 & $16.63 \%$ \\
& \multirow{3}{*}{50 Menit } & III & 21.413 & $26.85 \%$ \\
& & IV & 21.471 & $46.94 \%$ \\
& & V & 21.67 & $4.01 \%$ \\
\hline
\end{tabular}

Biodiesel dengan varian waktu reaksi selama 30 menit menghasilkan senyawa asam oleat metil ester $(\mathrm{m} / \mathrm{z}=296)$ yang merupakan senyawa yang memiliki puncak fragmentasi tertinggi diikuti oleh asam stearat metil ester $(\mathrm{m} / \mathrm{z}=298)$ dan asam palmitat metil ester $(\mathrm{m} / \mathrm{z}=270)$.

Salah satu senyawa hasil analisis GCMS berdasarkan fragmen-fragmen berikut adalah metil palmitat. Metil palmitat merupakan senyawa yang memiliki massa 270 dari hasil identifikasi GCMS. Berikut ini fragmen hasil GCMS dari metil palmitat. 


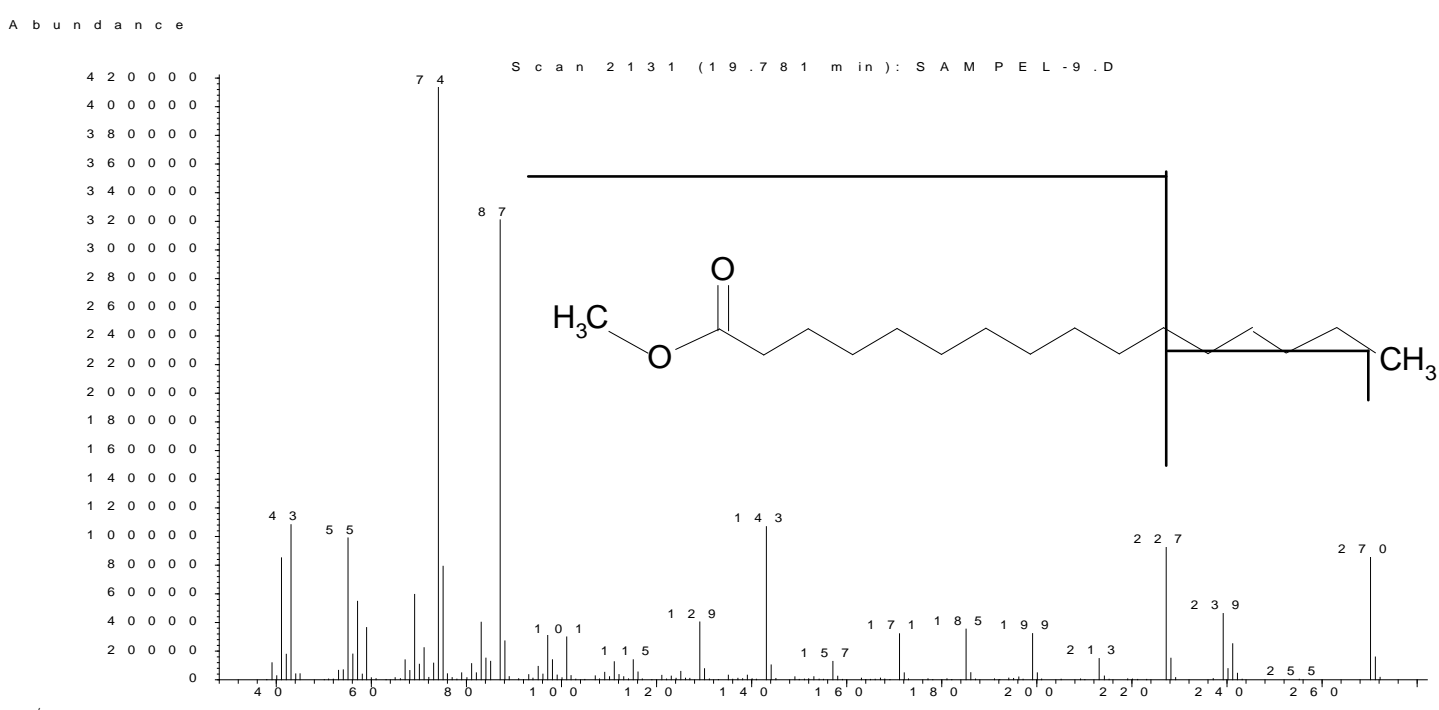

Gambar 1. Fragmentasi Metil Palmitat Hasil Identifikasi GCMS

Dalam GCMS, gas digunakan untuk membawa sampel melewati lapisan material. Gas yang bebas bergerak akan membawa sampel ke bagian stationary phase, lalu sebagian dari komponen sampel akan menempel pada stationary phase dan sebagian komponen lainnya akan bergerak lebih lama sehingga akan keluar komponen dari stationary phase pada waktu yang berbeda-beda. Dengan cara inilah komponen pada sampel dideteksi. Detector pada GCMS akan mendeteksi komponen senyawa yang diberi tambahan energi yang sangat besar sehingga atomatom pada molekul senyawa tersebut mengalami penguraian. Molekul-molekul organik yang terurai akan menghasilkan ion-ion dan dari ion-ion tersebut akan menghasilkan sinyal elektrik berupa fragmen-fragmen yang terlihat seperti gambar 1.

Metil palmitat yang terlihat pada gambar tersebut mengalami penguraian. Penguraian tersebut berdasarkan hasil deteksi GCMS dimana penguraian dari setiap puncak menunjukkan puncak ion molekul 270. Senyawa yang diidentifikasi berupa senyawa dengan rumus molekul $\mathrm{C}_{17} \mathrm{H}_{34} \mathrm{O}_{2}$. Senyawa yang paling mendekati jika dibandingkan dengan pola fragmentasinya adalah metil palmitat berdasarkan pola fragmennya 270 dan 227 memiliki selisih 43 dimana rumus molekul yang mirip dengan jumlah selisihnya adalah $\mathrm{C}_{3} \mathrm{H}_{7}$. Begitu pula pada pola fragmen 227-87 memiliki selisih 140 dimana rumus molekul yang mirip dengan jumlah selisihnya adalah $\left(\mathrm{CH}_{2}\right)_{10}$. 


\section{PENUTUP}

\section{Kesimpulan}

Nilai konversi produk biodiesel dari waktu reaksi 30, 40, 50 menit adalah 0,037 \%; 0,029 $\%$ dan $0,018 \%$. Komponen senyawa yang diperoleh dari hasil reaksi transesterifikasi adalah metil palmitat, metil oleat, metil elaidat, metil stearat dan metil linolenat.

\section{Saran}

Perlu dilakukan penelitian lebih lanjut menggunakan sonikator yang kapasitasnya lebih besar agar dapat memperoleh hasil yang maksimal.

\section{DAFTAR PUSTAKA}

Arlene, Ariestya, Suharto dan Jessica N.R. 2010. Pengaruh Temperatur dan Ukuran Biji Terhadap Perolehan Minyak Kemiri pada Ekstraksi Biji Kemiri dengan Penekanan Mekanis. Bandung. Hal: 1-3.

Craig, Elevitch dan Harley I.Manner. Aleurites moluccana (Kukui) in Species Profiles for Pasific Island Agroforestry. www.tradisionaltree.org. (Diakses tanggal 24 Januari 2014).

Departemen Agama RI. Al-Qur'an Al-Karim dan Terjemahnya. Semarang: PT. Karya Toha Putra. 1996.

Elviyanti. 2007. "Desain Sistem Penentuan Kualitas Biodiesel Berbasis Minyak Nabati." Tesis Pascasarjana Institut Pertanian Bogor, Bogor. Hal: 1.

Hambali, Erliza. Teknologi Bioenergi. Cet. 1; Jakarta: AgroMedia Pustaka. 2007.

Kementrian ESDM RI No. 723 K/10/DJE/2013. Standar dan Mutu (Spesifikasi) Bahan Bakar Nabati (Biofuel) Jenis Biodiesel Sebagai Bahan Bakar Lain yang Dipasarkan di Dalam Negeri. Jakarta: 2013.

Musadhaz, Sabinazan, Dwi Setyaningsih dan Djeni Hendra. 2012. "Pembuatan Biodiesel Biji Karet dan Biodiesel Sawit dengan Instrumen Ultrasonik Serta Karakteristik Campurannya." Bogor. 22 (3). Hal: 1.

Pamata, Nathasya. 2008. "Sintesis Metil Ester (Biodiesel) Dari Minyak Biji Kemiri (Aleurites moluccana) Hasil Ekstraksi Melalui Metode Ultrasonokimia.” Skripsi Sarjana, Fakultas MIPA UI. Jakarta. Hal: 25-32.

Sulistyo, Hary, et. al. 2009. "Crude Candlenut Oil Ethanolysis to Produce Renewable Energy at Ambient Condition.” San Francisco. 1. Hal: 1-5.

Yuliani, Fitri, et. al. 2013 "Pengaruh Katalis Asam $\left(\mathrm{H}_{2} \mathrm{SO}_{4}\right)$ dan Suhu Reaksi pada Reaksi Esterifikasi Minyak Biji Karet (Hevea brasiliensis) Menjadi Biodiesel.” Skripsi Sarjana, Fakultas Teknologi Industri ITS. Surabaya. Hal: 1-2 . 
